NBER WORKING PAPER SERIES

\title{
VALUING THE RELOAD FEATURES OF EXECUTIVE STOCK OPTIONS
}

\author{
Steven Huddart \\ Ravi Jagannathan \\ Jane Saly \\ Working Paper 7020 \\ http://www.nber.org/papers/w7020 \\ NATIONAL BUREAU OF ECONOMIC RESEARCH \\ 1050 Massachusetts Avenue \\ Cambridge, MA 02138 \\ March 1999
}

An earlier version of this paper, by Jagannathan and Saly, was titled "Ignoring reload features can substantially understate the value of executive stock option." Huddart extended the analysis to consider cases of multiple and unrestricted downloads. Jagannathan and Saly thank Bob McDonald for helpful discussions. Huddart particularly thanks Bob Whaley for helpful insights and encouragement. The views expressed in this paper are those of the authors and do not reflect those of the National Bureau of Economic Research.

(1) 1999 by Steven Huddart, Ravi Jagannathan, and Jane Saly. All rights reserved. Short sections of text, not to exceed two paragraphs, may be quoted without explicit permission provided that full credit, including ${ }^{\circledR}$ notice, is given to the source. 
Valuing the Reload Features of Executive Stock Options

Steven Huddart, Ravi Jagannathan, and Jane Saly

NBER Working Paper No. 7020

March 1999

JEL No. C80, D84, J33, M12, M41

ABSTRACT

Under Statement of Financial Accounting Standards No. 123, the grant date value of executive stock options excludes the value of any reload feature because, at the time of writing the standard in 1995, the Financial Accounting Standards Board believed it was not feasible to value a reload feature at the grant date. We show how the Binomial Option Pricing Model can be used to determine the grant date value of such options. Ignoring the reload feature can substantially understate the value of the option: the reload feature increases the value of an otherwise similar option by 24 percent in the example we consider. In view of the potential significance of the reload feature and the versatility of the Binomial Option Pricing Model, the Financial Accounting Standards Board may wish to reconsider the accounting for options with a reload feature.

Steven Huddart

Fuqua School of Business

Duke University

Box 90120

Durham, NC 27708-0120

huddart@mail.duke.edu

Jane Saly

3-122 Carlson School of Management

University of Minnesota

32119 th Ave S

Minneappolis, MN 55455

jsaly@csom.umn.edu
Ravi Jagannathan

J.L. Kellogg Graduate School of Mgmt. 2001 Sheridan Rd.

Leverone / Anderson Complex

Evanston, IL 60208-2001

and NBER

rjaganna@nwu.edu 


\section{INTRODUCTION}

Some executive stock options have features that conventional exchange-traded and over-the-counter options do not. These features may alter significantly the value of executive stock option grants compared to conventional options. Yet, for the reload feature, the Financial Accounting Standards Board (FASB) in 1995 recommended delaying estimation of the feature's value: ${ }^{1}$

The Board continues to believe that, ideally, the value of an option with a reload feature should be estimated at the grant date, taking into account all of its features. However, at this time, it is not feasible to do so. Accordingly, the Board concluded that the best way to account for an option with a reload feature is to treat both the initial grant and each subsequent grant of a reload option separately. (Statement of Financial Accounting Standards No. 123, \186, p. 61)

However, as Arnason and Jagannathan (1994) show, executive stock options and the reload feature can be valued using the Binomial Option Pricing method.

The Binomial Option Pricing Model (Cox et al., 1979) is sufficiently versatile to value executive stock options with a reload feature at the time of the initial grant. We present a method to value, at grant date, options that may be reloaded a fixed number

1 Other terms for reload options include restoration options, replacement options, continuation options, replenishment options, and accelerated ownership options. 
of times. We demonstrate the method using a Norwest Corporation option grant with a single reload. In this example, the value of the option with the reload feature is $24 \%$ more than the value of the same option without the reload feature. We further explain how our method generalizes to handle additional features of reload options including options for which the number of reloads is unrestricted. Accordingly, the full value of an option with a reload feature can be valued at the grant date.

A reload feature is a provision that stipulates new options are granted to an executive at the time the executive exercises the original options. The reload options typically have an exercise price equal to the then-current market price and expire at the same time as the original options. The number of reload options granted per option exercised varies by firm. Commonly, a reload option is granted for each share tendered by the executive in payment of the exercise price on the original options. ${ }^{2}$ Sometimes the new options themselves may be reloaded. Hence, a comprehensive valuation procedure requires that both the number of reloads allowed and the number of options granted per existing option exercised be taken into account. The procedure must also anticipate that a reload feature affects the timing of exercise of the initial option. The Black-Scholes formula cannot provide an accurate measure of the value of a reload feature since it neither anticipates optimal early exercise nor assigns value to the reloaded options.

2 Under some plans, the stock used to pay the exercise price must have been held by the cmployee for a minimum specified time. Fims may use this feature to induce executives to hold some of their wealth in stock in periods before the executive exercises his options. Some reload plans also require excutives to hold shares acquired on exercise for some time after exercise. See Hemmer et al. (1996). 
Hemmer et al. (1998) show that, if the number of reloads allowed is unrestricted and a new option is granted for every share tendered in payment of the exercise price, then it is optimal to exercise whenever the current stock price rises above the exercise price. This is a useful observation on the optimal exercise policy in this special limiting case, but many practical questions regarding valuation and optimal exercise strategy cannot be addressed using their approach. Hemmer et al. do not address exercise policy when the options may only be reloaded a fixed number of times or when the number of new options granted differs from the number of shares tendered in payment of the exercise price. In this paper, we provide an algorithm that determines the grant date valuation of an option with a reload feature for which the number of reloads is restricted. The algorithm provides grant date values for any prescribed formula of new options granted per option exercised. We further show how the algorithm, with a slight modification, also values options when the number of reloads is unrestricted. Computationally, this method differs from the one proposed in Hemmer et al., but provides the same result in the cases they consider.

Section two reports on the prevalence and terms of reload features. Section three applies the Binomial Option Pricing Model to our example; describes the optimal excrcise policy for an option with a reload feature; and, illustrates how additional opportunities to reload an option increase its grant-date value. Section four presents a sensitivity analysis of the value of a reload feature when dividends, volatility, term 
to expiration, number of options granted at reload, and number of reloads allowed are varied. Section five discusses some limitations and extensions of the algorithm. Section six concludes the paper.

\section{PREVALENCE AND TERMS OF RELOAD OPTIONS}

Reload features are used by larger firms in almost all areas of business as shown in tables 1 and 2. From 1992 to 1997, a rising fraction of all option grants to executives are grants of reload options (i.e., the original option has been exercised). Firms in which reload options have been triggered tend to be larger with almost double the annual sales of other firms. In addition, grants of reload options are more common in financial services than in other categorics. Since firms only report figures for reloads after the feature is triggered, there must be more options outstanding that have a reload feature that has not yet been triggered.

The possibility to reload an option increases its value compared with an otherwise identical option that cannot be reloaded, which we call a conventional option. The holder of an option with a reload feature benefits since he may exercise existing options to lock in a gain and still participate in future potential gains. The optimal time to excreise the original option and the value of the reload feature depend on two key terms of the option reload provision: (i) the number of times the option may be reloaded, and (ii) the number of new options granted for each option exercised. 
There is considerable variation in these terms across reload options. As regards the number of reloads, Norwest Corporation allows only one reload, First Bank Systen allows up to three reloads, and First Chicago places no limit on the number of times an option may be reloaded. As regards the number of new options granted, Amgen offers new options equal in number to the shares tendered in payment of the excrcise price, whereas First Bank System and Norwest Bank offer new options granted equal in number to the shares tendered to pay both the exercise price and any taxes that become duc on exercise.

\section{USING THE BINOMIAL OPTION PRICING MODEL}

\section{Overview}

Our algorithm is a variation of the standard Binomial Option Pricing Mcthod. ${ }^{3}$ Fundamental to Binomial Option Pricing Model is the idea that stock price movements are woll-approximated by assuming the stock price can only move to two possible values in a short interval of time. The first step is to construct a price tree that probabilistically describes future stock price movements over time. The time from the grant date to the expiration of the options is divided into short periods. Over each period, the stock price is assumed to cither rise or fall by a fixed factor with a fixed probability. Every node in the tree corresponds to a particular time to expiration and stock price level.

3 See Cox and Rubinstein (1985) for an excellent discussion of the use of Binomial Option Pricing Model for valuing other complex options. 
Each node in one time period is connected to two nodes in the next time period, representing a rise or fall in the stock price by a fixed factor. Next, the value of the option is calculated at each node, working backwards recursively from the expiration date. At cxpiration, valuing the option is straightforward. At each earlier node, the value of the option can be determined from a particular recursive equation that depends only on the (already computed) values of successor nodes and parameters used to describe the stock price tree. The value of the option at every node is determined by computing the value at expiration, and then working backward to nodes one period prior to expiration, then two periods prior to expiration, and so on.

The recursive equation compares the value of holding the option for one more period to the value of exercising the option immediately and sets the value at that node to the larger of these quantities. The value from immediate exercise is the difference between the market price and the exercise price, plus the expected value of reload options received on exercise. The value of holding the option until the next period is the discounted and weighted sum of the value of the option if held one more period in the case the stock price rises and the value of the option if held one inore period in the case the stock price falls. The weights reflect the likelihood the stock will rise (or fall). The discount factor is one plus the riskless interest rate. The value of the option on tho grant date is the value at the starting node of this tree. Optimal carly exercise is incorporated by assuming that the holder will exercise whenever the value of exercising 
is higher than the value of holding. Since the decision to exercise or hold is made at each node, optimal early exercise is embedded in the valuation. By including the value of reloaded options in the exercise value, the reload feature is embedded in the valuation as well. A recursive formula summarizes the calculation.

The appendix provides a simple, 3-period example of the calculations involved in this model. ${ }^{4}$ For those who wish to implement the algorithm to value the options with the reload feature, the next section presents the method in detail. The reader can omit this section without loss of continuity.

\section{Mathematical Development}

The Binomial Option Pricing Model uses the Black-Scholes (1973) option valuation assumptions. In particular, the riskless rate of interest, $r^{*}$, is assumed to be constant, and asset prices are assumed to be lognormally distributed with a constant volatility rate, $\sigma{ }^{5}$ Certain notation and definitions facilitate the description of the binomial method. Let $X$ be the option's exercise price. Define $N$ to be the total number of time steps during the life of the option, and $T$ to be the option's time to expiration. in ycars. At each step, the asset return is either $u=\exp (\sigma \sqrt{T / N})$, with probability $p=(1+r-d) /(u-d)$, or $d=1 / u$, with probability $1-p$, where $r=\left(1+r^{*}\right)^{T / N}-1$. Let $S_{i}^{j}$ denote the stock price $i$ time steps before expiration when the stock price has risen $j$

4 For a tutorial approach to this model and its application to valuation of executive stock options see Arnason and Jagannathan (1994).

5 See Cox and Rubinstein (1985) for details. 
times (net) since the grant date. ${ }^{6}$ For a stock that pays no dividends, the stock price at node $(i, j)$ is $S_{i}^{j}=S_{N}^{0} u^{j}$, where $S_{N}^{0}$ is the stock price at node $(N, 0)$, which corresponds to the grant date. For a dividend-paying stock, this expression generalizes to $S_{N}^{0} f(i, j)$ where

$$
f(i, j) \equiv u^{j}(1-y)^{d(i)}
$$

$y$ is the quarterly dividend expressed as a constant fraction of the stock price, and the cxponent $d(i)$ is the number of dividend payments made since the grant date up until time $i$.

Let $C_{i}^{j}$ be the value of a conventional call option value at node $(i, j)$. Working backward from the end of the call option's life, $C_{i}^{j}$ is the maximum of the proceeds from immediate exercise and the expected present value of the possible option values at $i-1$.

$$
C_{i}^{j}=\max \left\{\begin{array}{l}
S_{i}^{j}-X, \\
\frac{p C_{i-1}^{j+1}+(1-p) C_{i-1}^{j-1}}{1+r} .
\end{array}\right.
$$

By moving backward through time and repeating these computations, the current value of an American-style option is determined.

This basic method has been used to value conventional options for twenty years. To generalize the valuation method to handle reloads, it is necessary to write down the recursive equation that values an option at time $i$ as the greater of the proceeds from

6 Negative values of $j$ mean the stock price has fallen since the grant date. For example, if thrce periods after the grant date there have been two down moves and onc up move, then the stock price is $S_{N-3}^{-1}=u^{-1} S_{N}^{0}$. 
excrcise, plus the value of new options granted as a result of the reload provision; and, the cxpected payoff from holding option until the next period, $i-1$.

Elaborating on the notation above, let $C_{i}^{j}\left(m, S_{N}^{0}, X\right)$ be the value of an option that may be reloaded $m$ times, has grant date stock price $S_{N}^{0}$ and strike price $X$, at node $(i, j)$ in a binomial tree. The value of the an option at node $(i, j)$ is the maximum of the value of the option if exercised, plus the value of the reload options, if any; and, its value if held for one more period, which is a weighted discounted sum of the option's value given either an uptick or downtick. This value can be expressed recursively as

$$
C_{i}^{j}\left(m, S_{N}^{0}, X\right)=\max \left\{\begin{array}{l}
S_{i}^{j}-X+Z C_{i}^{0}\left(m-1, S_{i}^{j}, S_{i}^{j}\right), \\
\frac{p C_{i-1}^{j+1}\left(m, S_{N}^{0}, X\right)+(1-p) C_{i-1}^{j-1}\left(m, S_{N}^{0}, X\right)}{1+r}
\end{array}\right.
$$

where $Z$ is the number of new options granted per old option exercised. When the number of new options granted equals the number of shares needed to pay the exercise price, $Z=X / S_{i}^{j}$. Since $m=-1$ implies that no more reloads are allowed, it is understood that $C_{i}^{j}\left(-1, S_{i}^{j}, S_{i}^{j}\right)=0$ for all $i$ and $j$. At cxpiration, the option must be excrcised. so for all $j, k, m$, and $X$

$$
C_{0}^{j}\left(m, S_{k}^{0}, X\right)=\max \left(0, S_{0}^{j}-X\right)
$$

To reduce the number of binomial trees that must be constructed and evaluated. it is computationally efficient to standardize by the strike price $X$. Define

$$
c_{i}^{j}(m, x) \equiv C_{i}^{j}\left(m, S_{N}^{0} / X, 1\right)=\frac{C_{i}^{j}\left(m, S_{N}^{0}, X\right)}{X}
$$


where $x \equiv S_{N}^{0} / X$, the ratio of the stock price at the date of grant to the exercise price. In practice, the excrcise price of most grants is equal to the stock price on the date of grant; hence, $x=1$. For premium options (i.e., those that are out-of-the-money on the date of grant), $x$ is less than one. In this notation, the grant date value of an option struck at-the-money that cannot be reloaded (i.e., a conventional option) is written $X c_{N}^{0}(0,1)$. The function $c$ is interpreted as the value of an option per dollar of the strike price. Analogous to equation (2), the option's value, per dollar of the inital strike price, is conveniently rewritten as

$$
c_{i}^{j}(m, x)=\max \left\{\begin{array}{l}
x f(i, j)-1+Z^{*} c_{i}^{0}(m-1,1), \\
\frac{p c_{-1}^{j+1}(m, x)+(1-p) c_{i-1}^{j-1}(m, x)}{1+r},
\end{array}\right.
$$

where $Z^{*} \equiv Z S_{i}^{j} / X$ is the number of new options granted per old option exercised multiplied by the ratio of the stock price at time $i$ to the strike price of the existing options. In the case where the number of new options granted is equal to the shares tendered to pay the exercise price, $Z^{*}=1$. Computer code implementing this algorithm in the form of a Mathematica notebook may be downloaded from littp://fac141.fuqua.duke.cdu/Papers/Out/Reload.nb

\section{Example}

Wo use the example of $\mathrm{Mr}$. R. Kovacevich, CEO of Norwest Corporation, to illustrate valuation of an option with a reload feature using the Binomial Option Pricing Morlel. In 1991, Kovacevich was granted 138,000 options to buy stock at $\$ 14.53$ per 
share. The options became exercisable in 1994 and have a one-time reload option if previously owned shares are used to purchase the option.

Norwest grants reload options equal to the number of shares tendered to pay the exercise price plus any taxes owed in connection with the exercise. ${ }^{7}$ These reload options have the same expiration date as the original options and an exercise price equal to the stock price on the day the reload feature is triggered. Since only one reload is allowed. the reload options themselves do not have a reload feature.

If Kovacevich chooses to exercise the options upon vesting in 1994 when the stock price is $\$ 26$, he will pay to the corporation $138,000 \times \$ 14.53=\$ 2,005,140$ and receive 138,000 shares, each worth $\$ 26$ or $\$ 3,588,000$ in total. Assuming that the marginal income tax rate for Kovacevich is $48.1 \%$, the tax payable upon exercising the options will be $0.481 \times(\$ 26-\$ 14.53) \times 138,000=\$ 761,356$. If Kovacevich pays the exercise price and taxes with shares he already owns (each worth $\$ 26$ ), he will have to pay a total of $\$ 2,005,140+\$ 761.356=\$ 2,766,496$ with 106,404 shares (i.e., $\$ 2,766,496$ divided by $\$ 26$ per share). Thus, Kovacevich gives up his 138,000 options and 106,404 shares of stock to the company, and receives in return 138,000 shares of stock and 106,404 new options with an exercise price of $\$ 26$ and 7 years to expiration.

Using equation (3) to value the option as of May 1991 requires the following inputs: the current stock price at the date of the grant, $\$ 14.53$; the exercise price, $\$ 14.53$; the

7 The difference between the market price of the stock on the date of exercise and the excrcise price is income to the employee on the date of exercise. See IIuddart (1998). 
time to expiration, 10 years; the dividend yield, $3 \%$; the annual stock price volatility, $27.3 \%$; and, the risk-free rate, $7 \%$ simple interest. We represent stock price movements over the life of the option using a binomial tree with one step per month. If Kovacevich exercises at node $(i, j)$, he receives $Z=\left[X+.481\left(S_{i}^{j}-X\right)\right] / S_{i}^{j}$ reload options per option he exercises, since $48.1 \%$ is his marginal tax rate. ${ }^{8}$ The grant-date value of a conventional option with the above assumptions is $\$ 5.23$. Adding the reload feature increases the option's value by $24 \%$ to $\$ 6.49$. If the executive only receives $X / S_{i}^{j}$ new options per original option exercised (i.e., the number of new options granted is not increased by the amount of taxes the executive on exercise of the original grant), the reload feature adds $14 \%$ to the value of a conventional option.

Figure 1 plots the optimal exercise region in (stock price, time) space assuming a single reload is allowed on a stock that pays no dividends. The figure shows that excrcise depends on both the stock price level and time remaining to expiration. The longer the time to expiration, the higher the threshold stock price at which exercise is optimal.

\section{Extension to an Unrestricted Number of Reloads}

If the number of times the option can be reloaded is unrestricted, a modification of the recursive equation $(3)$ is required. Let $c_{i}^{j}(A, x)$ denote an option that may be reloaded an arbitrary number of times. Simply substituting $c_{i}^{j}(A . \cdot)$ in $(3)$ wherever

\footnotetext{
8 See Appendix 2 in Arnason and Jagannathan (1994).
} 
$c_{i}^{j}(m, \cdot)$ or $c_{i}^{j}(m-1, \cdot)$ appears yields a system that cannot be solved recursively. This is because $c_{1}^{0}(A, 1)$ is expressed as a function of itself, as are option values at other nodes in the tree. The key simplification comes from observing that

$$
c_{i}^{0}(A, 1)=\frac{p c_{i-1}^{1}(A, 1)+(1-p) c_{i-1}^{-1}(A, 1)}{1+r}
$$

since the executive is indifferent between holding and exercising an at-the-money option that can be reloaded an unrestricted number of times. Substituting the right hand side of this equality wherever the left hand side appears in equation (3) yields

$$
c_{i}^{j}(A, x)=\max \left\{\begin{array}{l}
x f(i, j)-1+Z^{*} \frac{p c_{i-1}^{1}(A, 1)+(1-p) c_{i-1}^{-1}(A, 1)}{1+r}, \\
\frac{p c_{i-1}^{j+1}(A, x)+(1-p) c_{i-1}^{j-1}(A, x)}{1+r}
\end{array}\right.
$$

which can be solved recursively since $c_{i}^{j}(A, x)$ is expressed in terms of successor nodes in the tree for all $i$ and $j$. So, the grant date value can be determined by computing the values of nodes in a single binomial tree, working backwards from the expiration date. This means the valuation of an option that may be reloaded an arbitrary number of times is no more complex computationally than valuing a conventional option using the binomial method.

\section{SENSITIVITY ANALYSIS}

For options with either a 5 or 10 -year life, table III presents the value of a reload option granted-at-the-money for stock volatilities ranging between 20 and 50 percent per 
year, annual dividend yields ranging from zero to five percent, and up to five reloads.

An interest rate of $7 \%$ is assumed for all calculations. The values in the table are stanclardized by the grant date market value of the stock. Thus, reading from the table, the grant-date value of a 5-year conventional option on a stock paying no dividend with a market value of $\$ 17$ and a volatility of $20 \%$ is $\$ 17 \times .335$, or $\$ 5.70$. Similarly, the grantdate value of an otherwise identical option that may be reloaded five times is $\$ 17 \times .400$, or $\$ 6.80$, which is $19 \%$ more.

\section{Dividends}

Dividends have a large impact on the value of the reload feature. While the value of the conventional option falls with increases in dividend payout, the value of the reload feature increases as a percent of the value of the conventional option.

The ratio of reload option value to conventional option value can be used to assess when the reload feature is most valuable. In contrast to the $19 \%$ increase in value attributable to the reload feature for the option on a no-dividend stock calculated above, on an otherwise identical stock with a dividend yield of $5 \%$, a 5 -year option that may be reloaded 5 times is worth $28 \%$ more than a conventional option since $226 / .177=1.28$. Thus, the reload feature is worth more for options on high dividend stocks. Since an increase in dividends reduces the value of an option, the value of a reload feature as a percent of the conventional option value increases with increases in dividend yield.?

9 Reload features are more common in larger companies and financial services businesses. These firms tend to pay higher-than-average dividends. 


\section{Volatility}

The table also reveals that reload features represent a higher fraction of an option's total value for high volatility stocks. For a low volatility stock paying no dividend, the reload feature adds $19 \%$ to a conventional option's value, as calculated above. For a high volatility $(\sigma=50 \%)$ stock, the reload feature adds $23 \%$ to a 5 -year conventional option's value since $.640 / .520=1.23$

\section{Time to Expiration}

Third, the table shows that the reload feature adds more to a conventional option's value for short-maturity options. Again as calculated above, for a low volatility stock that pays no dividend, the reload feature adds $19 \%$ to a conventional option's value. For a 10 year option on the same stock, the reload feature adds $11 \%$ to a conventional option's value since $.582 / .523=1.11$.

\section{Number of Reload Options Granted}

While the table does not show it, the value of a reload feature increases with the number of reload options granted. If, in the Norwest cxample, Kovacevich received rcload options equal in number to the shares required just to pay the excrcise price, the value of such options would be $\$ 5.99,15 \%$ higher than an otherwise similar conventional option. This compares with the $\$ 6.49$ value of Kovacevich's actual options. ${ }^{10}$

10 Using the same kind of analysis it can be shown that reload fcatures are a higher fraction of total option value for discount options (i.e., options where the strike price is below the grant-date stock price) than for premium options. 


\section{Number of Reloads}

The effect of increasing the number of times an option may be reloaded on the value of the option is shown in figure 2 using the stock parameters of Norwest and the reload factor, $Z$, of Kovacevich's options. An option that may reloaded once is worth $\$ 1.27$ or $24 \%$ more than a conventional option. Each additional time the option may be reloaded adds value to the option but at a decreasing rate: a second opportunity to reload is worth $\$ 0.47$ and a third opportunity to reload is worth $\$ 0.22$. An option that may be reloaded an arbitrary number of times is worth $\$ 7.37$, or just $\$ 0.20$ more than an option that can be reloaded only three times.

\section{Frequency of Steps in the Algorithm}

The accuracy of the valuation increases with the number of times each year that the binomial tree allows the stock price to vary. All calculations in this paper are based on binomial steps of one month, i.e., the stock is modeled as varying twelve times per year. This represents a good tradeoff between accuracy of the valuation and the processing resources required to compute values. As the number of times the option may be reloaded grows large, the computation time required to value the option also grows bccanse each time the option can be reloaded requires an additional tree to be generated. Even for 10 reloads the computational demands are not excessive-all values presented in this paper were computed on a desktop computer. 
In summary, the reload feature adds $24 \%$ to the value of a conventional option in our example. In other cases, this amount may be more or less depending on the characteristics of the underlying stock and the terms of the option. The incremental value depends on the number of times reloads are allowed, the size of the dividend payout, the number of years the option is outstanding, the exercise price, the number of reload options and the volatility of the underlying stock.

\section{LIMITATIONS AND EXTENSIONS}

We have implicitly assumed the executive's risk aversion is the same as that of an average trader in the market who holds the stock, that the executive will remain employed with the firm throughout the option life, and that neither liquidity needs nor behavioral decision biases will cause the exccutive to exercise the option earlier than our model determines is optimal. ${ }^{11}$ Thus, our method values a hypothetical tradable option that has the reload feature. The value to the executive need not be the same as the value of a hypothetical tradable option since the executive cannot trade his options; instead he must excrcise while the holder of a traded option could sell. In addition, there are legal restrictions that prevent the executive from diversifying away the unsystematic risk in these options as an independent trader could do. These differences imply that theorctical models designed to value traded options yield valuations strictly greater than the value to the executive. ${ }^{12}$

\footnotetext{
11 Nevertheless, these factors are likely to be important. See Ileatl et al. (1999) for a discussion of behavioral factors.

12 See Huddart (1994).
} 
On behalf of the corporation, the net cost of the options may be less than the value to an independent trader who assumes the granting of options does not affect the value of the stock. If the executive is likely to exercise the option for any of the reasons listed above, then the fair value of the option to the employer corporation is reduced.

The purpose of granting options is to provide incentives to the executive to increase the value of the firm. In essence, the shareholders give up some share of the pie in order to increase the overall value of the pie. In addition, when executive stock options are excrcised, the corporation issues new stock diluting current ownership. This paper ignores these issues. Instead, we calculate the value of an option with a reload feature ignoring potential feedback from incentives provided by options to the stock price process.

The method can readily be modified to handle vesting and stock performance restrictions on exercise. ${ }^{13}$ For instance, in the case of time-based vesting restrictions, in those periods that the options are not exercisable, the value of the option is just the holding value; the value from exercising is ignored. It is also possible to modify the model to account for the executive's risk preferences, liquidity needs, and the probability of cmployment termination. The difficulties presented by these latter three factors lie in reliably estimating parameters that capture risk aversion, liquidity needs, and the likelihood of termination, not in implementing the valuation when these parameters are known. ${ }^{1 \cdot 1}$

\footnotetext{
13 A typical executive option cannot be exercised prior to vesting. Thus, the option is forfeited if the executive leaves the firm prior to vesting.

14 See Carpenter (1998) and Cuny and Jorion (1995).
} 
These limitations to analytical valuation methods are not unique to reload options; they are shared by conventional options, too. SFAS 123 suggests estimating the time to expiration of options based on historical patterns of exercise. ${ }^{15}$ However, as Kulatilaka and Marcus (1994) point out, this approach can lead to biased estimates of the value. Hemmer, Matsunaga and Shevlin (1994) show that use of an expected time to exercise can impart substantial upward bias in the estimated option value. The Binomial Option Pricing Model can be modified to take these possibilities into account in a way that avoids these sources of bias.

\section{CONCLUSION}

SFAS 123 states, "... ideally, the value of an option with a reload feature should be estimated at the grant date, taking into account all of its features..." $(\boldsymbol{\Upsilon} 186$, p. 61). However, without a method to estimate its value, the FASB recommended ignoring the value of the reload feature until a reload grant is triggered (i.e., when the original option is first exercised). This paper shows how the Binomial Option Pricing Model can be used to value the reload feature at the date of the initial grant. The reload feature adds significant value to the underlying option-24\% in our example. In view of this, the Financial Accounting Standards Board may wish to reconsider its recommendation regarding the valuation of the reload feature.

$\overline{15}$ Huddart and Lang (1996) document patterns of exercise and their association to
volatility, past stock price movements, and the lapsing of vesting restrictions. 
Our algorithm can also characterizes the optimal exercise policy for options with the reload feature, as we show in figure I. Knowledge of the optimal exercise policy obviously lias value to the holders of reload options.

Compensation consultants may wish to understand how the value of the reload feature varies with the terms of the options and the characteristics of the underlying stock. The percentage value that a reload feature adds to a conventional option decreases with the time to expiration; and increases with the number of reloads allowed, the number of new options granted at reload, and the ratio of market to strike price of the original option. Although a compensation committee can customize an option's terms including the strike price, expiration date, number of reloads and number of new options granted at reload, the committee generally is unable to alter dividends and volatility. The reload feature is a higher fraction of an option's value for firms where the underlying stock pays high dividends or has high volatility. This may increase the attractiveness of reload options to some executives and some firms. 


\section{Appendix I. Using the Binomial Option Pricing Model}

The appendix illustrates the application of the Binomial Option Pricing Model to the valuation of reload options.

The main steps are: (1) calculate the stock price tree, (2) value a conventional option, (3) value the opportunity to reload the option one time by scaling the values calculated in step (2), and (4) value the option with a reload feature by adding the value of a reload option to the proceeds from exercise at each node.

For expositional convenience, we value an option to buy one share at an exercise price of $\$ 10.00$ with three years to expiration. The grant date stock price is $\$ 10.00$, the annual volatility is $30 \%$, the firm pays no dividends, and $N=3$ periods. Thus, the up factor is $u=\exp (.30 \times 1)=1.35$, the down factor is $d=1 / 1.35=.741$, and the riskneutral probability of an uptick is $p=.54$.

\section{Calculate the Stock Price Tree}

Table A1 presents the array of possible stock prices for the 3 periods. The stock price $i$ periods before expiration given $j$ net upticks since the grant date is $S_{i}^{j}=\$ 10.00 \times$ $u^{j}$. At node A, the current stock price, $S_{3}^{0}$, is $\$ 10.00$ per share. Thus, stock price at

node B, $S_{2}^{1}$, is $\$ 10.00 \times 1.35=\$ 13.50$ and at node C, $S_{2}^{-1}$, price is $\$ 10.00 \times .741=\$ 7.41$. and so on. 


\section{Value a Conventional Option}

Now assume that you have an option to purchase one share for $\$ 10.00$ within the next 3 time periods. The value $C_{i}^{j}$ at a given node, described by the remaining time to maturity, $i$, and the net number of upticks since the grant date, $j$, is determined by computing the value at expiration, $i=0$, and then working backward to $i=1$, $i=2$, and so on. At each node, the holder has the choice of exercising or holding the option. The value of exercising, $V^{x}$, is the greater of 0 and the difference between the market price and the exercise price. Thus, at expiration node $G$, the exercise value of the option, $V^{x}$, is $\$ 24.60-\$ 10.00=\$ 14.60$ and at expiration node $I$, the exercise value of the option, $V^{x}$, is $\$ 0.00$ since exercising would result in a loss of $\$ 7.41-\$ 10.00=-\$ 2.59$.

The value of holding the option is determined by the expected payoff from holding the option for one more period

$$
V^{h}=\frac{p C_{i-1}^{j+1}+(1-p) C_{i-1}^{j-1}}{1+r}
$$

where $p=.54$ is the probability of an uptick and $r=7 \%$ is the risk-free interest rate.

The calculations at node D in table A1 are

$$
V^{h}=\frac{.54 \times \$ 14.60+.46 \times \$ 3.50}{1.07}=\$ 8.87
$$

and

$$
V^{x}=\$ 18.23-\$ 10.00=\$ 8.23 .
$$


Thus, $C_{1}^{2}=\$ 8.87$ because $V^{h}>V^{x}$. Hence, it is optimal to hold rather than exercise the option at node D. Exercise is worthwhile only at expiration nodes $\mathrm{G}$ and $\mathrm{H}$. In the absence of dividends, the value of exercising a conventional option before expiration is always less than the value of holding.

\section{Value the Opportunity to Reload the Options}

Now assume that the holder gets a reload grant of one share for each original option when he exercises the option prior to expiration. Using the notation in the body of the paper, these assumptions correspond to $Z=1$ and $m=1$. The value of the reload option at node $\mathrm{D}$ is the same as the value of a conventional option granted at node D with an exercise price of $\$ 18.23$ and 1 period to expiration. Table A2 shows the value trees for the reload options issued at nodes D and B. The calculations for the holding value of a reload option at node $\mathrm{D}$ (see panel 1) are

$$
\begin{aligned}
V^{h} & =\frac{.54 \times \$ 6.37+.46 \times \$ 0.00}{1.07}=\$ 3.21, \\
V^{x} & =\$ 18.23-\$ 18.23=0, \quad \text { and } \\
C_{1}^{0} & =\$ 3.21 .
\end{aligned}
$$

Since the holder receives one option for each option exercised, the value, $V^{R}$, of the reload option at node $\mathrm{D}$ is $\$ 3.21$. If the holder received a fraction of a reload option for cach original option exercised, then the value of the reload would be that fraction times the value of one reload option. The calculations are similar for the value of the reload 
option issued at node B. Table A3 shows the value of a reload option issued at each node.

\section{Value of the Option with a Reload Feature}

To value the original option with the reload feature, the value of a reload option, $V^{r}$. is added to the exercise value of the original option for the same node, consistent with equation (2). The value of the option at that node is still the maximum of the holding value and the exercise value including the value of a reload option. One still works backward from the value at expiration. Thus, the holding value of an option with a reload feature differs from the holding value of a conventional option because the former depends on the value of reload options at successor nodes.

Table A4 presents the value of an option that may be reloaded once. The values at expiration do not change from the value of a conventional option because both the original and the reload options expire at $i=0$. At node $\mathrm{D}$, the exercise value of the option is now $\$ 8.23+\$ 3.21=\$ 11.44$. Thus, the value of exercising is greater than the value of holding and the option value at node $\mathrm{D}$ is $\$ 11.44$. This increases the holding value at node $\mathrm{B}$ from $\$ 5.24$ to $\$ 6.53$.

The value of the option with a reload feature is $\$ 3.68$ at node $\mathrm{A}$. The value of the same option without a reload feature is $\$ 3.03$ at node $A$. The difference is $\$ .65$ or a $21.5 \%$ increase in value due to the addition of a reload feature. Also note that the addition of a reload feature leads to early exercise at node D whereas early exercise was never optimal without the reload feature. 


\section{References}

Arnason, S. and R. Jagannathan. 1994. Evaluating executive stock options using the binomial option pricing model. Teaching Note, University of Mimesota.

Black, F. and M. Scholes. 1973. The pricing of options and corporate liabilities. Journal of Political Economy, 81 (May-June): 637-654.

Carpenter, J. N. 1998. The exercise and valuation of executive stock options. Joumal of Financial Economics 48 (May): 127-158.

Cox, J. C., S. A. Ross, and M. Rubinstein. 1979. Option pricing: a simplified approach. Journal of Financial Economics 7 (September): 229-263.

Cox, J. and M. Rubinstein. 1985. Option Markets. New Jersey: Prentice-Hall.

Cuny, C. J. and P. Jorion. 1995. Valuing executive stock options with a departure decision. Journal of Accounting and Economics 20 (September): 193-205.

Financial Accounting Standards Board. 1995. Accounting for Stock-based Compensation. Statement of Financial Accounting Standards No. 123. Norwalk. CT: Financial Accounting Standards Board.

Heath, C., S. Huddart, and M. Lang. 1999 Psychological factors and stock option exercise. Quarterly Journal of Economics (in press).

Huddart, S. 1994. Employee Stock Options. Journal of Accounting and Economics 18 (September): 207--231.

Huddart, S. and M. Lang 1996. Employee stock options exercises: An empirical analysis. Journal of Accounting and Economics 21 (February): 5-43.

Huddart, S. 1998. Tax planning and the exercise of employee stock options. Contemporary Accounting Research 15 (Summer): 203-216.

Hemmer, T., S. Matsunaga, and T. Shevlin. 1994. Estimating the "fain value" of employee stock options with expected early exercise. Accounting Horizons 8 (December): $23-42$.

Hemmer, T., S. Matsunaga, and T. Shevlin. 1996. An empirical examination of reload employee stock options. (October) Working paper, University of Washington.

Hemmer, T., S. Matsunaga, and T. Shevlin. 1998. Optimal exercise and the cost of cmployee stock options with a reload provision. Journal of Accounting Resentr 36 (Fall): 231-255.

Kulatilaka, N. and A. Marcus. 1994. Valuing employee stock options. Financial Analysts Journal (November-December): 46-56. 


\section{Table I \\ Prevalence of reload option grants ${ }^{\mathrm{a}}$}

\begin{tabular}{cccc}
\hline Year & $\begin{array}{c}\text { Number of } \\
\text { option grants }\end{array}$ & $\begin{array}{c}\text { Number of } \\
\text { reload grants }\end{array}$ & $\begin{array}{c}\text { Reload grants as a } \\
\text { percent of option grants }\end{array}$ \\
\hline 92 & 4,488 & 246 & 5.5 \\
93 & 6,884 & 353 & 5.1 \\
94 & 7,599 & 397 & 5.2 \\
95 & 7,719 & 397 & 5.1 \\
96 & 9,642 & 931 & 9.7 \\
97 & 9,673 & 1,135 & 11.7 \\
\hline
\end{tabular}

a Source-Standard \& Poor's Execucomp Database. The number of reload grants is the total number of grants that are grants of reload options. 


\section{Table II \\ Prevalence of reload option grants by industry}

\begin{tabular}{|c|c|c|c|c|}
\hline Industry & $\begin{array}{l}\text { Number of } \\
\text { firms with } \\
\text { no reload }\end{array}$ & $\begin{array}{l}\text { Median sales } \\
\text { (millions } \$ \text { ) }\end{array}$ & $\begin{array}{l}\text { Number of } \\
\text { firms with at } \\
\text { least } 1 \text { reload }^{\mathrm{c}}\end{array}$ & $\begin{array}{l}\text { Median sales } \\
\text { (millions } \$ \text { ) }\end{array}$ \\
\hline Primary industry & 83 & 1,080 & 4 & 7,509 \\
\hline Transportation & 42 & 1,483 & 2 & 26,031 \\
\hline Trade & 257 & 826 & 13 & 1,128 \\
\hline Food and Drug & 83 & 2,405 & 5 & 8,741 \\
\hline Services & 52 & 339 & 2 & 4,964 \\
\hline Oil and gas & 79 & 496 & 5 & 2,656 \\
\hline Financial services & 176 & 690 & 27 & 3,863 \\
\hline Manufacturing & 173 & 620 & 10 & 3.498 \\
\hline Computers & 234 & 448 & 8 & 666 \\
\hline Health care & 20 & 353 & 0 & NA \\
\hline Utilities & 114 & 1,491 & 6 & 6,887 \\
\hline SIC code changed in $1992-1997$ & 395 & 756 & 23 & 2,691 \\
\hline All industries & 1,708 & 749 & 105 & 2,926 \\
\hline
\end{tabular}

a Source-Standard \& Poor's Execucomp Database.

b. Includes all firms granting at least one executive options during 1992-1997.

c Includes all firms that granted reload options because a reload feature was triggered. 


\section{Table III \\ Reload Option Values}

\begin{tabular}{|c|c|c|c|c|c|c|c|c|c|c|c|c|}
\hline \multirow[t]{3}{*}{ Volatility } & \multirow{3}{*}{$\begin{array}{l}\text { Number of } \\
\text { reloads } \\
\text { allowed }\end{array}$} & \multicolumn{6}{|c|}{ Dividend yield } & \multicolumn{5}{|c|}{ Dividend yield } \\
\hline & & .00 & .01 & .02 & .03 & .04 & .05 & .00 & $.01 \quad .02$ & .03 & .04 & \\
\hline & & & $(5-$ & 9 & ant & & & & $(10-y e$ & 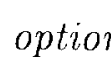 & & \\
\hline \multirow[t]{7}{*}{.20} & 0 & .335 & .295 & .259 & .227 & .200 & .177 & .523 & $.437 \quad .365$ & .305 & .259 & .221 \\
\hline & 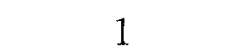 & .363 & .321 & .286 & .256 & .230 & .207 & .547 & $.464 \quad 398$ & .343 & .297 & .259 \\
\hline & 2 & .378 & .332 & .296 & .267 & .241 & .219 & .561 & $.474 \quad .409$ & .356 & .311 & .273 \\
\hline & 3 & .388 & .338 & .301 & .271 & .245 & .223 & .571 & .478 .413 & .360 & .315 & .277 \\
\hline & 4 & .395 & .341 & .303 & .273 & .248 & .226 & .577 & $.480 \quad .415$ & .363 & .318 & .281 \\
\hline & 5 & .400 & .343 & .304 & .274 & .249 & .226 & .582 & $.481 \quad .416$ & .363 & .319 & .281 \\
\hline & estr & .419 & .344 & .305 & .275 & .249 & .226 & .604 & $.482 \quad .417$ & .364 & .319 & .281 \\
\hline \multirow[t]{7}{*}{.30} & 0 & .394 & .357 & .323 & .293 & .268 & .247 & .580 & $.499 \quad .433$ & .381 & .339 & .304 \\
\hline & 1 & .437 & .400 & .368 & .339 & .314 & .293 & .618 & $.546 \quad .487$ & .437 & 395 & .358 \\
\hline & ( & .459 & .418 & .385 & .357 & & .31 & & $.563 \quad .504$ & .456 & 414 & .378 \\
\hline & 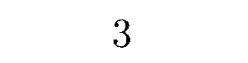 & .472 & .428 & .393 & .364 & .338 & .31 & & $.572 \quad .512$ & .464 & .422 & .385 \\
\hline & 4 & .481 & .434 & .398 & .368 & .343 & .32 & & $.576 \quad .516$ & .468 & .426 & .390 \\
\hline & 5 & .487 & .437 & .400 & .370 & .345 & .322 & .664 & $.578 \quad .518$ & .470 & .428 & .391 \\
\hline & ostri & .511 & .442 & .402 & .372 & .346 & .323 & .690 & $.581 \quad .520$ & .471 & .429 & .392 \\
\hline \multirow[t]{7}{*}{.40} & 0 & .457 & .421 & .389 & .361 & .336 & .314 & .643 & .566 .505 & .457 & .416 & .382 \\
\hline & 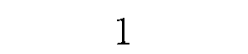 & .511 & .476 & .446 & .419 & .394 & .37 & .690 & $.625 \quad .570$ & .524 & .484 & .449 \\
\hline & 2 & .536 & .499 & .468 & .441 & .416 & .3 & .712 & $\begin{array}{lll}646 & .592\end{array}$ & .547 & .508 & .473 \\
\hline & 3 & .551 & .512 & .479 & .451 & .425 & .40 & .725 & $\begin{array}{lll}656 & .602\end{array}$ & .557 & .517 & .481 \\
\hline & 4 & .561 & .518 & .484 & .456 & .431 & .40 & .733 & $.661 \quad .607$ & .562 & .522 & .487 \\
\hline & 5 & .568 & .523 & .488 & .459 & .433 & .41 & .740 & $.664 \quad .610$ & .564 & .525 & .490 \\
\hline & unrestricted & .593 & .530 & .491 & .461 & .435 & .412 & .765 & $\begin{array}{ll}668 & .612\end{array}$ & .566 & .526 & .491 \\
\hline \multirow[t]{7}{*}{.50} & 0 & .520 & .483 & .453 & .426 & .402 & .38 & .705 & $.631 \quad .574$ & .527 & .489 & .454 \\
\hline & 1 & .580 & .547 & .518 & .492 & .469 & .44 & .754 & $\begin{array}{ll}695 & .645\end{array}$ & .601 & .564 & .529 \\
\hline & 2 & .607 & .573 & .543 & .517 & .494 & .47 & .776 & $.718 \quad .669$ & .626 & .589 & .556 \\
\hline & 3 & .623 & .587 & .556 & .528 & .504 & .48 & .789 & $.728 \quad .680$ & .637 & .600 & .56 \\
\hline & 4 & .633 & .594 & .562 & .535 & .511 & .48 & .797 & $.734 \quad .684$ & .642 & .605 & .572 \\
\hline & 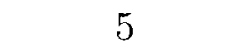 & .640 & .599 & .566 & .538 & .513 & .4 & .803 & $.737 \quad .688$ & .645 & .608 & .575 \\
\hline & unrestricted & .665 & .607 & .570 & .541 & .515 & .492 & .825 & $.741 \quad .690$ & .647 & .610 & .576 \\
\hline
\end{tabular}

a Values are computed using the Binomial Option Pricing Model for grants of options with varying restrictions on reloads, volatilities of the underlying stock, dividend yields, and times to expiration. All options have strike prices equal to the market price on the grant date. Assumes one new option is granted on reload for each share of stock surrendered in payment of the exercise price and an annual interest rate of $7 \%$. Zero reloads correspond to conventional employee stock options. Values are as at the grant date, and are expressed per dollar of stock price on the grant date. The binomial trees used to produce these estimates have one step per month. 
Figure I

Optimal exercise region for an option that may be reloaded once

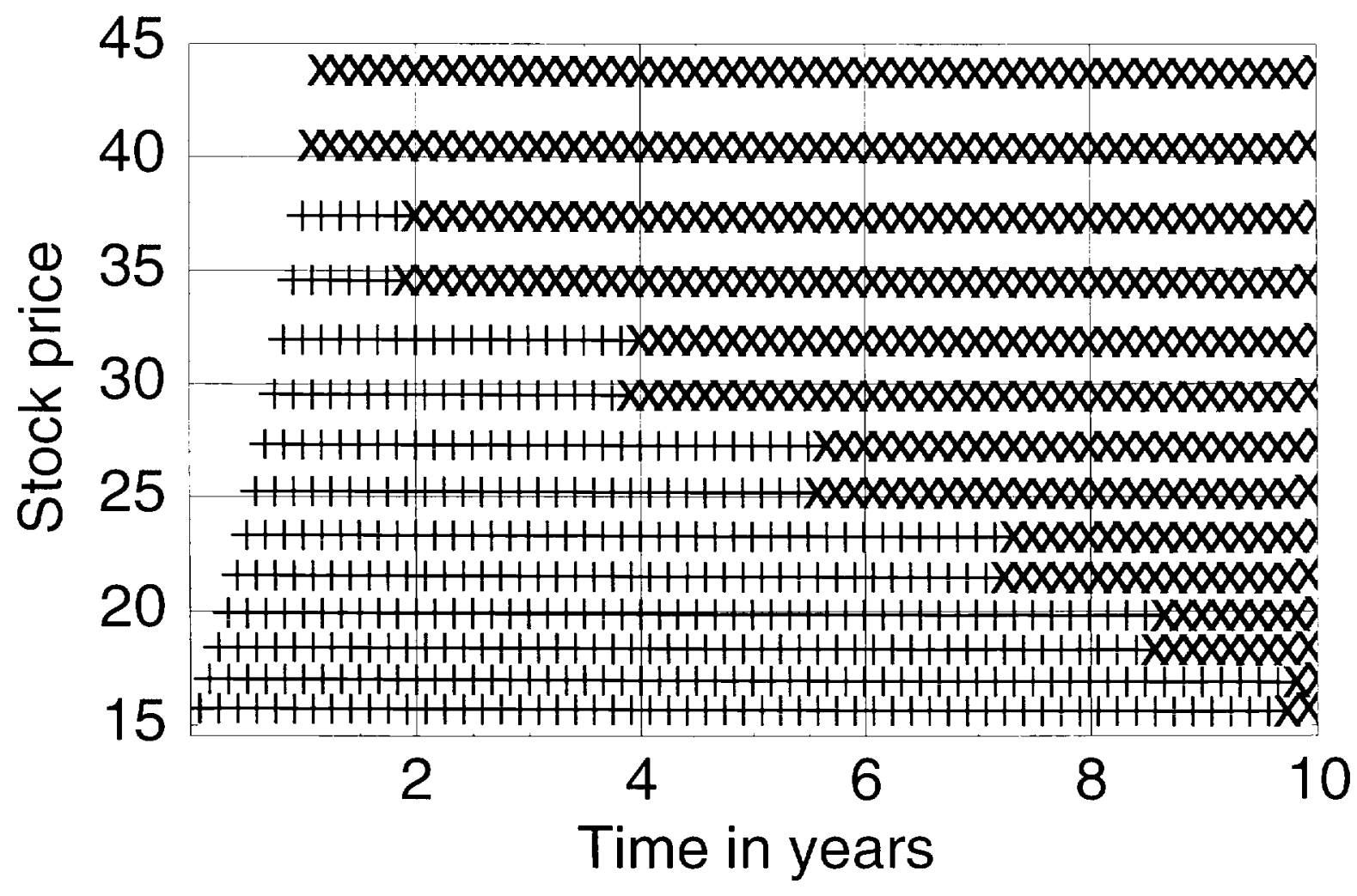

Assuming no dividends, volatility of $27.3 \%$, an interest rate of $7 \%$, strike and grant date stock prices of $\$ 14.53$, and the reload factor, $Z$, of Kovacevich's options, this figure plots the optimal exercise region in a binomial tree for an option that may be reloaded once. Optimally, exercise occurs when the stock price first passes into a node coded ' $x$ '. In regions coded ' + ', it is optimal to hold the option until the next period. Since it is not optimal to exercise when the option is out of the money, stock prices below the strike price are not plotted. The binomial trees used to produce these estimates have one step per month. 


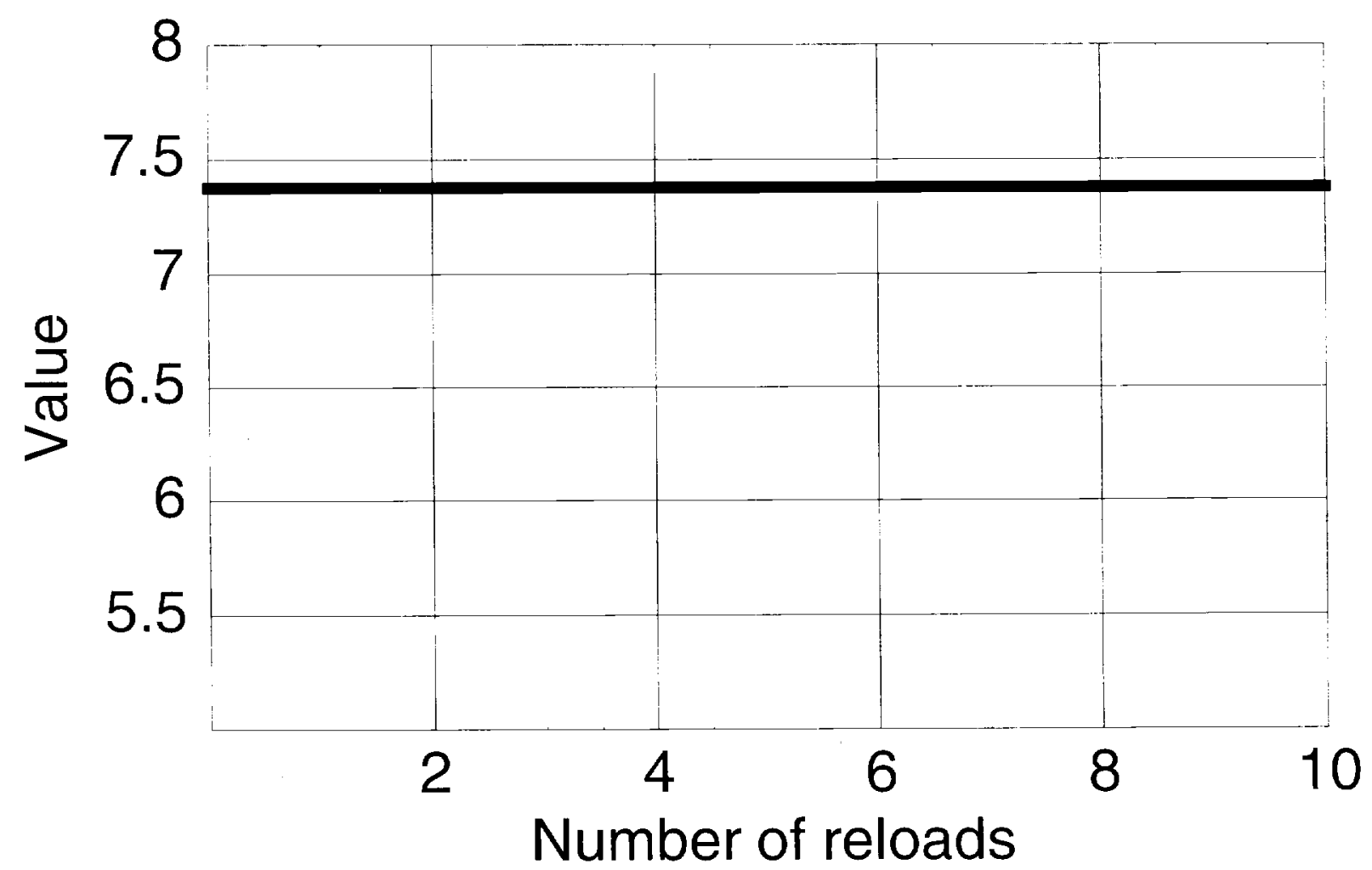

This figure plots grant-date value in dollars of options with a strike price equal to the grant-date stock price of $\$ 14.53$ and a 10 year life as a function of the number of times the option may be reloaded. The stock parameters are those of Norwest (i.e., a $3 \%$ dividend yield and volatility of $27.3 \%$ ). A $7 \%$ interest rate is assumed. The reload factor, $Z$, corresponds to Kovacevich's options as described in the text. The horizontal line in the figure is the value of options that may be reloaded an arbitrary number of times. The binomial trees used to produce these estimates have one step per month. 


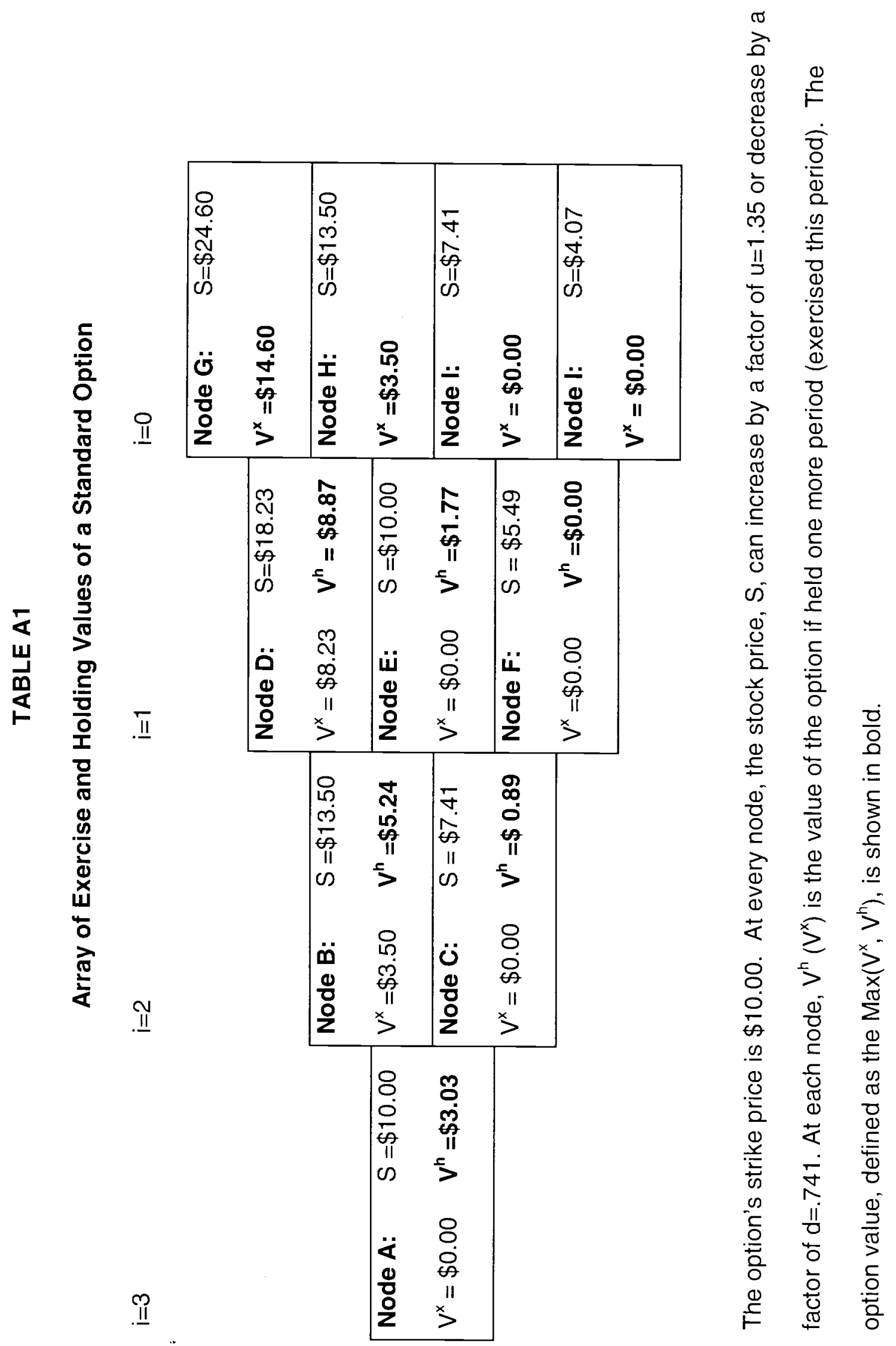


TABLE A2

Values for Reload Options Issued at Nodes B and D

Panel 1: Value of a reload option issued at node $D$ with an exercise price of $\$ 18.23$ and 1 period to expiration:

$$
\mathrm{t}=2 \quad \mathrm{t}=3
$$

\begin{tabular}{|c|c|c|c|}
\hline & & Node G: & $\mathrm{S}=\$ 24.60$ \\
\hline Node D: & $S=\$ 18.23$ & $V^{x}=\$ 6.37$ & \\
\hline$V^{x}=\$ 0.00$ & $v^{h}=\$ 3.21$ & Node H: & $S=\$ 13.50$ \\
\hline & & $V^{x}=\$ 0.00$ & \\
\hline
\end{tabular}

Panel 2: Value of a reload option issued at node $B$ with an exercise price of $\$ 13.50$ and 2 periods to expiration:
$i=2$
$i=1$
$i=0$

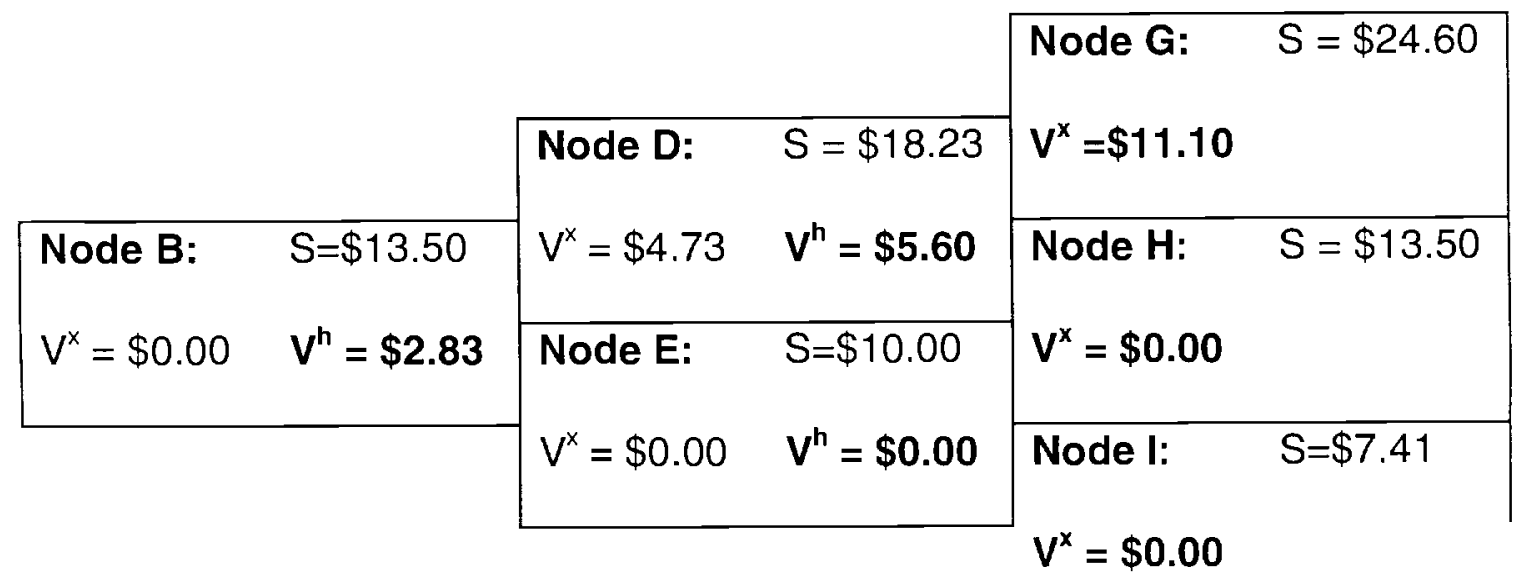

